Türkiye Jeoloji Bülteni
Geological Bulletin of Turkey
$63(2020) 117-124$
doi: $10.25288 / \mathrm{tjb} .585304$

\title{
Güllük Körfezi (Muğla-Türkiye) Yüzey Sedimentlerinde Toksik Metal Kirliliği
}

Toxic Metal Pollution in the Surface Sediments from Güllük Bay (Muğla-Turkey)

\author{
Nuray Çağlar (Balkıs) $)^{1 *} \mathbb{D}$, Abdullah Aksu1 ${ }^{1}$, Gülşen Altuğ $\breve{2}^{(\mathbb{D}}$ \\ ${ }^{I *}$ Istanbul Üniversitesi, Deniz Bilimleri ve İşletmeciliği Enstitüsü, İstanbul

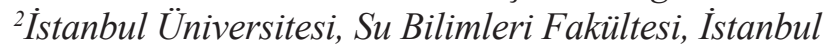

\author{
Geliş/Received : 01.07.2019••üzeltilmiş Metin Geliş/Revised Manuscript Received : 07.08.2019 • Kabul/Accepted : 15.10 .2019 \\ • Çevrimiçi Yayın/Available online : 15.01.2020 • Bask1/Printed : 31.01 .2020
}

Araştırma Makalesi/Research Article Türkiye Jeol. Bül. / Geol. Bull. Turkey

Öz: Bu çalışmada yaz aylarında yoğun nüfusa, kış aylarında ise düşük nüfusa sahip, yakın çevresinde termik santral bulunan Güllük Körfezi'ndeki yüzey sedimentlerinin kurşun $(\mathrm{Pb})$, kadmiyum $(\mathrm{Cd})$, krom $(\mathrm{Cr})$, bakır $(\mathrm{Cu})$, çinko $(\mathrm{Zn})$, arsenik (As) ve alüminyum (Al) içerikleri incelenmiştir. Bu amaçla körfezden 2011-2012 yılları arasında Mayıs, Haziran, Temmuz ve Eylül aylarında yüzey sediment örnekleri alınmıştır. Liyoflizatörde kurutulan örneklere mikrodalgada kuvvetli asit $\left(\mathrm{HNO}_{3}+\mathrm{HF}+\mathrm{HClO}_{4}\right)$ çözünürleştirmesi uygulanmıştır. Güllük Körfezi yüzey sedimentlerinde atomik absorpsiyon spektrofotometresi ile belirlenen toplam metal konsantrasyonları sirasiyla $\mathrm{Pb}$ için 1 ile $209 \mu \mathrm{g} / \mathrm{g}$; Zn için 10 ile $259 \mu \mathrm{g} / \mathrm{g}$; Cu için 1 ile $59 \mu \mathrm{g} / \mathrm{g}$; Cr için 0,1 ile $46 \mu \mathrm{g} / \mathrm{g}$; Cd için <0,01 ile $2,8 \mu \mathrm{g} / \mathrm{g}$, As için $<0,01$ ile $0,4 \mu \mathrm{g} / \mathrm{g}$ ve Al için $\% 0,6$ ile \%5,9 arasında değiştiği tespit edilmiştir. Tüm ölçüm dönemlerinde körfez sedimentlerinin $\mathrm{Cu}, \mathrm{Cr}$ ve As elementleri yönünden kirlenmemiş olduğu, buna karşılık $\mathrm{Pb}, \mathrm{Cd}$ ve $\mathrm{Zn}$ elementleri yönünden ise orta derecede kirlenmiş olduğu belirlenmiştir. Yüzey sedimentlerindeki yüksek $\mathrm{Pb}$, Cd ve Zn değerleri Güllük Körfezi'ne özellikle Sarıçay deresi olan karasal kaynaklı antropojenik (evsel+endüstriyel) girdilere, limanlardaki deniz taşımacılığına ve turizm aktivitelere işaret etmektedir. Artan nüfus yoğunluğuna (283,6 kişi/m²) (TÜiK, 2018) bağlı olarak insan aktiviteleri de körfezdeki metal kirliliğini etkilemektedir.

Anahtar Kelimeler: Metal kirliliği, sediment, Güllük Körfezi.

\begin{abstract}
In this study, total lead (Pb), cadmium (Cd), chromium (Cr), copper (Cu), zinc ( $\mathrm{Zn}$ ), arsenic (As) and aluminum (Al) contents were investigated in surface sediments in order to determine the current pollution in Güllük Bay, which has dense population in summer, low population in winter, and a thermal power plant in the vicinity. For this purpose, surface sediments were collected from the bay seasonally in 2011 and 2012. Strong acid $\left(\mathrm{HNO}_{3}+\mathrm{HF}+\mathrm{HClO}_{4}\right)$ digestion was used for metal analysis after drying in a freeze-dryer. Total metal concentrations were measured by atomic absorption spectrophotometer. The total metal contents changed between 1 and $209 \mu \mathrm{g} / \mathrm{g}$; 10 and $259 \mu \mathrm{g} / \mathrm{g} ; 1$ and $59 \mu \mathrm{g} / \mathrm{g}$; 0.1 and $46 \mu \mathrm{g} / \mathrm{g}$; $<0.01$ and $2.8 \mu \mathrm{g} / \mathrm{g},<0.01$ and $0.4 \mu \mathrm{g} / \mathrm{g}$ and $0.6 \%$ and $5.9 \%$ for $\mathrm{Pb}, \mathrm{Zn}, \mathrm{Cu}, \mathrm{Cr}, \mathrm{Cd}, \mathrm{As}$ and $\mathrm{Al}$, respectively. $\mathrm{Cu}, \mathrm{Cr}$ and As concentrations were lower than the background values, contrary to higher $\mathrm{Pb}, \mathrm{Cd}$ and $\mathrm{Zn}$ contents in bay surface sediments during all sampling periods. These high metal values indicate the presence of anthropogenic (domestic and industrial) inputs via Sarcçay creek and both maritime transport and tourism waste in Güllük Bay. As a result, it was found that population growth and human activities affected metal contamination.
\end{abstract}

Keywords: Metal pollution, sediment, Güllük Bay. 


\section{GíRiş}

Deniz suyunda metallerin kaynağı doğal ya da antropojenik kökenlidir. Bunlar; karalar üzerindeki zengin metal kaynaklarından atmosfer yoluyla olan taşınımlar, akarsularla olan girdiler, denizaltı hidrotermal ve volkanik aktiviteler, diyajenez gibi doğal ve jeokimyasal prosesler ve hızla artan nüfus ile insan aktiviteleridir. Maden cevherlerinin erozyonu, volkanik aktiviteler, toz bulutları, orman yangınları ve tarım gibi doğal kaynakların ve insan aktiviteleri sonucu oluşan girdilerin etkileri değerlendirildiğinde ise metal girdileri karmaşık bir hal alır (Balkıs ve Algan, 2005). Bunun yanı sira metalik maden sahalarından sizan metallerin nehir bünyesine ve oradan da denizlere taşınması ile metal birikimine önemli ölçüde katkıda bulunur. Ayrıca kentsel ve endüstriyel bölgelerden geçen nehirlere atıkların deşarjı sonucu metalleri bünyesine alır. Bir diğer metal kaynağ 1 ise atmosferik girdilerdir. Metalleri diğer toksik maddelerden ayıran en önemli özellikleri ise insanlar tarafindan ne oluşturulabilir ne de yok edilebilir olmalarıdır. Tüm canlıların yaşamsal faaliyetlerini normal olarak sürdürebilmeleri için, ortamlarında bulunan $\mathrm{Cu}, \mathrm{Mn}, \mathrm{Zn}$ ve diğer metallere $(\mathrm{Cd}, \mathrm{Cr}, \mathrm{Fe}, \mathrm{Mo}$, $\mathrm{Ni}$, Sn ve V) belirli düzeylerde gereksinim duymaktadır. $\mathrm{Bu}$ metaller organik moleküllerle ve daha çok proteinlerle birleşerek metal-protein komplekslerini oluştururlar. Bunun yanında, birçok enzimin yapılarına katılırlar. Örneğin, Fe kanı kırmızı olan canlılarda, $\mathrm{Cu}$ ise renksiz kan sıvisı olan omurgasızlarda ve deniz organizmalarında oksijen taşımaları ve bunların yanında diğer birçok enzim aktivitelerine direkt olarak metalloprotein olarak katılırlar (Gailer, 2007). Bununla beraber, bazı metaller de vitaminlerin yapı taşlarını oluştururlar (Güler ve Çobanoğlu, 1994). Esansiyel olan metaller, eksikliklerinde olduğu gibi fazla miktarlarda alındıklarında da toksik etki oluşturabilmektedirler. Toksiklik düzeyi her metalde farkl1lık göstermektedir. Metallerin toksiklik düzeyleri çoktan aza doğru
As, $\mathrm{Hg} \mathrm{Ag}, \mathrm{Cu}, \mathrm{Cd}, \mathrm{Zn}, \mathrm{Pb}, \mathrm{Cr}$, Ni ve Co şeklinde olmakla beraber bu siralama kesin değildir. Yüksek konsantrasyonlardaki metaller organizma için faydalı olsun olmasın toksiktir (Brayn, 1971; 1976). Bu nedenle hızla gelişen endüstrileşme ve artan nüfusla birlikte özellikle kıyısal sularda ve körfezlerde oluşan metal kirlenmesi dünyanın çeşitli bölgelerinde önemli halk sağlı̆̆ sorunları yaratmıştır. Ege Denizi'nde yapılan kirlilik çalışmalarında midyede oldukça yüksek poliaromatik hidrokarbon değerlerine rastlanmıştır (Balcıoğlu vd., 2014). Ayrıca evsel ve endüstriyel atıklar Marmara Denizi'ndeki $\mathrm{Pb}$ ve Cr kirliliğini tetiklemektedir (Aksu ve Taşkın, 2012). Sadece toksik metaller değil $\mathrm{Al}, \mathrm{Fe}, \mathrm{Mn}$ gibi metallerin dağılımı da evsel ve endüstriyel aktivitelerden redoks değişimleri sonucunda etkilenmektedir (Taşkın vd., 2011).

Güllük Körfezi, Torba, Güvercinlik ve Güllük gibiküçük yerleşimyerlerine sahip olup, çevresinde endüstriyel faaliyetler bulunmamaktadır (Şekil 1). Buna karşılık Güllük Limanı, özellikle çevredeki boksit ve feldspat rezervlerinin sevk noktası olması sebebiyle hayli işlek ve gelişmiştir. Limanın dışında balıkçılık ve turizm önemli faaliyet alanları ve geçim kaynaklarıdır. Kentin kuzeyine kurulu dalyanda ve denizde iyi balık çıkmakta, en çok, çipura, levrek, sargoz, mercan, lüfer, kefal, dil balığg, istavrit, palamut, yılanbalığ ve daha birçok türde balık avlanmaktadır. Ayrıca çevredeki koyların çoğunda kültür balıkçılığı da yapılmakta, çipura ve levrek yetiştirilmektedir. (Altuğ vd., 2013). Ancak, körfez tarım ve turizme ait aktiviteler, evsel atıklar, limanlardaki özellikle de Güllük Limanı'ndaki yoğun maden taşımacılığ ve Sarıçay deresinin getirdiği karasal girdiler sonucunda son yıllarda kirlenme tehlikesiyle karşı karşıyadır. $\mathrm{Bu}$ çalışmada Güllük Körfezi’nden 2011-2012 yılları arasında örnekleme yapılan yüzey sedimentlerinde kurşun $(\mathrm{Pb})$, çinko $(\mathrm{Zn})$, bakır $(\mathrm{Cu})$, krom $(\mathrm{Cr})$, kadmiyum $(\mathrm{Cd})$ ve arsenik (As) gibi bazı toksik metallerin güncel kirlenme seviyeleri ve kökenleri belirlenmeye çalışılmıştır. 


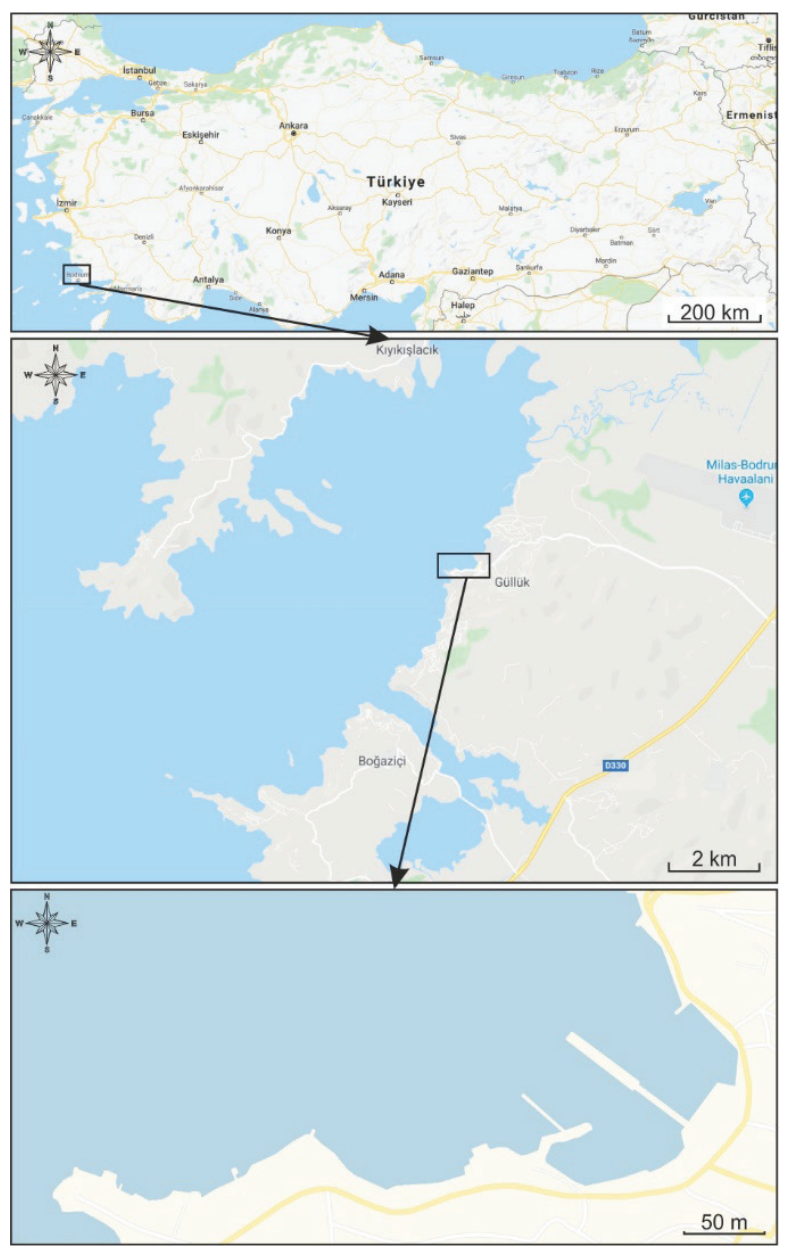

Şekil 1. Güllük Körfezi’nin konumu ve çalışma alanı.

Figure 1. Location map for Güllük bay and study area.

\section{MATERYAL VE METOT}

Bu çalışmada Güllük Körfezi'nden 2011-2012 yılları arasinda Mayss, Haziran, Temmuz ve Eylül dönemlerinde yüzey sediment örneklemesi yapılmıştır(Şekil 2 ve 3). Sediment örnekleriliman, koy (14 adet) ve kiyısal alandan (9 adet) Ekman Grab (Hydrobios 15x15) ile alınmış ve laboratuarda analiz edilinceye kadar $+4^{\circ} \mathrm{C}$ 'de saklanmıştır. Daha sonra liyoflizatörde kurutulan örneklere mikrodalgada kuvvetli asit $\left(\mathrm{HNO}_{3}+\mathrm{HF}+\mathrm{HClO}_{4}\right)$ çözünürleştirmesi uygulanmıştır (Loring ve Rantala, 1992; Li vd., 2000). Elde edilen örnekler $1 \mathrm{M} \mathrm{HCl}$ ile $10 \mathrm{ml}$ 'ye tamamlandiktan sonra $\mathrm{Cr}$,
$\mathrm{Cu}, \mathrm{Pb}$ ve $\mathrm{Zn}$ analizi İstanbul Üniversitesi Deniz Bilimleri ve İşletmeciliği Enstitüsü Kimyasal Oşinografi Anabilim Dalı'nda bulunan atomik absorbsiyon spektrofotometresinde (Shimadzu AA-6701-F, Japonya) hava-asetilen alevinde, Al analizi $\mathrm{N}_{2} \mathrm{O}$-asetilen alevinde, As analizi alevli hidrür ünitesinde analiz gerçekleștirilmiştir.

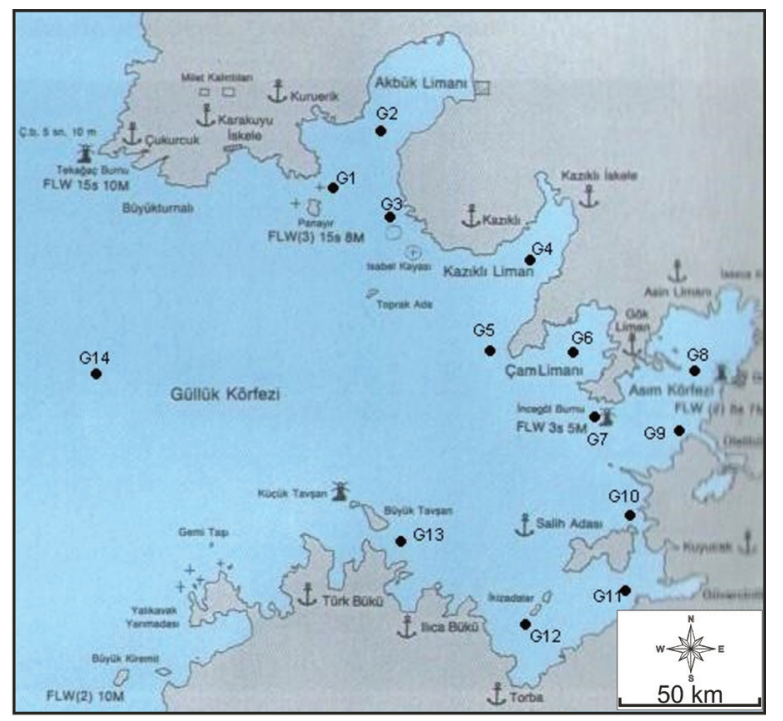

Şekil 2. Örnekleme istasyonları

Figure 2. Sampling stations

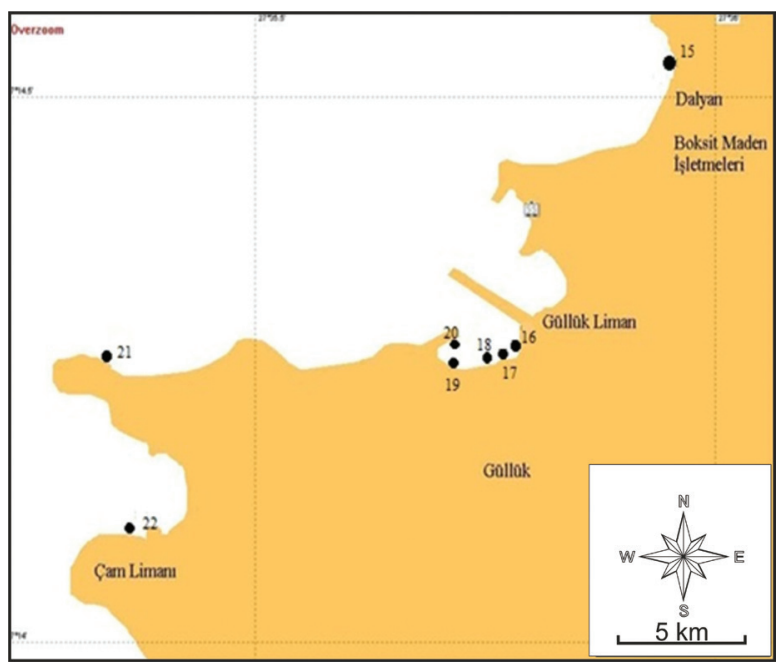

Şekil 3. Kıyısal alan örnekleme istasyonları.

Figure 3. Sampling stations in the coastal area. 


\section{BULGULAR}

Güllük Körfezi’nin liman, koy ve kıyısal alanlarından toplanan yüzey sediment örneklerinde toplam $\mathrm{Pb}, \mathrm{Cu}, \mathrm{Zn}, \mathrm{Cr}, \mathrm{Cd}$, As ve $\mathrm{Al}$ içerikleri grafikler halinde verilmiştir. Buna göre; körfezde alınan sediment örneklerinin toplam $\mathrm{Pb}$ içerikleri 1 ile $209 \mu \mathrm{g} / \mathrm{g}$ arasında değişmektedir (Şekil 4). En yüksek Pb içeriği Sarıçay deresi ağzında ilkbahar ve yaz mevsimlerinde, en düşük değer ise tüm örnekleme dönemlerinde (ilkbahar-yaz-sonbahar) Akbük Limanı açığı Panayır Adası kuzeyinde tespit edilmiştir. Ayrıca Kazıklı ve Çam Liman içlerinde de şeyl ortalamasının $(20 \mu \mathrm{g} / \mathrm{g})$ üzerinde $\mathrm{Pb}$ birikimleri belirlenmiştir. Krauskopf (1979) tarafindan belirtilen şeyl değerlerine göre tüm metal değerleri karşılaştırılmıştır. Buna karşılık körfezin genelinde ise $\mathrm{Pb}$ konsantrasyonunun $20 \mu \mathrm{g} / \mathrm{g}$ değerinin altında olduğu görülmüştür. Körfezde alınan sediment örneklerinin toplam Zn içerikleri 10 ile $259 \mu \mathrm{g} / \mathrm{g}$ arsında değişmektedir (Şekil 5). En yüksek Zn değeri sonbaharda Güllük Limanı halk plajlarında belirlenirken, en düşük değer İncegöl Burnu'nda ölçülmüştür. Körfezin büyük bölümünde de şeyl ortalaması olan $90 \mu \mathrm{g} / \mathrm{g}$ değerinin üzerinde tespit edilmiştir.

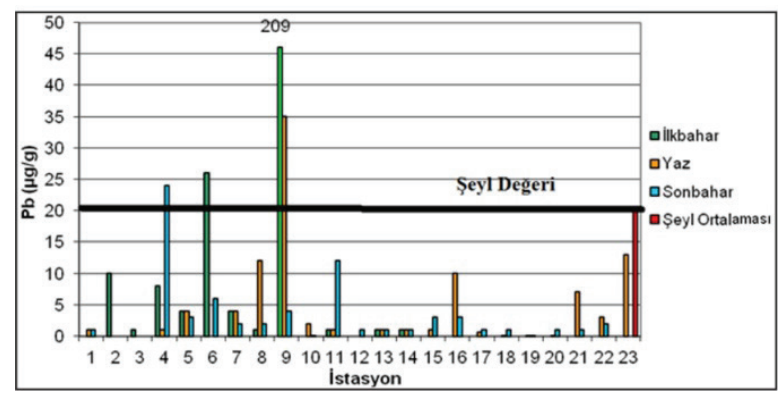

Şekil 4. Güllük Körfezi yüzey sedimentlerinde $\mathrm{Pb}$ içerikleri $(\mu \mathrm{g} / \mathrm{g})$.

Figure 4. Pb contents in surface sediments from Güllük Bay $(\mu g / g)$.

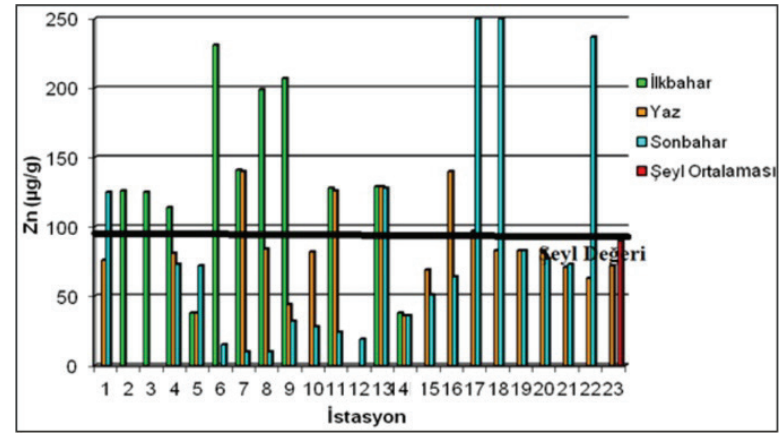

Şekil 5. Güllük Körfezi yüzey sedimentlerinde $\mathrm{Zn}$ içerikleri $(\mu \mathrm{g} / \mathrm{g})$.

Figure 5. Zn contents in surface sediments from Güllük Bay $(\mu g / g)$.

Körfez sedimentlerinde toplam $\mathrm{Cu}$ içerikleri 1 ile $59 \mu \mathrm{g} / \mathrm{g}$ arasında değişmektedir (Şekil 6). Bakır konsantrasyonları en yüksek değerde ilkbaharda Çam Limanı içinde ölçülürken, en düşük değerde yine aynı mevsimde Akbük liman içinde belirlenmiştir. Özellikle Çam liman içi, Asım Körfezi ve Sarıçay deresi ağzı dışında ise $\mathrm{Cu}$ değerleri şeyl ortalaması olan $50 \mu \mathrm{g} / \mathrm{g}$ 'ın altında tespit edilmiştir. Körfezde toplam krom içerikleri 0,1 ile $46 \mu \mathrm{g} / \mathrm{g}$ arasında değişmekte olup, şeyl ortalaması olan $100 \mu \mathrm{g} / \mathrm{g}$ değerinin oldukça altındadır (Şekil 7). Yüzey sedimentlerinde toplam Cd içerikleri $<0,01$ ile $2,8 \mu \mathrm{g} / \mathrm{g}$ arasında değişmektedir (Şekil 8). Bunun yanı sıra $\mathrm{Cd}$ değerlerinin Güllük Limanı'ndaki kıyısal alanın büyük bir bölümünde ve referans istasyonda ölçüm limitlerinin $(<0,01 \mu \mathrm{g} / \mathrm{g})$ altında olduğu görülmüştür. Özellikle en yüksek değerde $\mathrm{Pb}$ değişimlerine benzer şekilde Sarıçay deresi ağzında ölçülmüştür. Ayrıca Çam Limanı ve Güvercinlik’te de şeyl ortalaması olan $0,2 \mu \mathrm{g} / \mathrm{g}$ değerinin oldukça üzerinde tespit edilmiştir. Körfez sedimentlerinde toplam As içerikleri körfezin tamamında şeyl ortalamasının $(<10 \mu \mathrm{g} / \mathrm{g})$ altında ölçülmüştür. Güllük Körfezi yüzey sedimentlerinde $\mathrm{Al}$ içeriklerinin \%0,6 ile \%5,9 arasında değiştiği belirlenmiştir (Şekil 9). Buna göre Al değerleri tüm istasyonlarda şeyl ortalamasının $(\% 9,2)$ altındadır ve sedimentler ağırlıklı olarak kaba taneli malzemeden oluşmaktadır. 


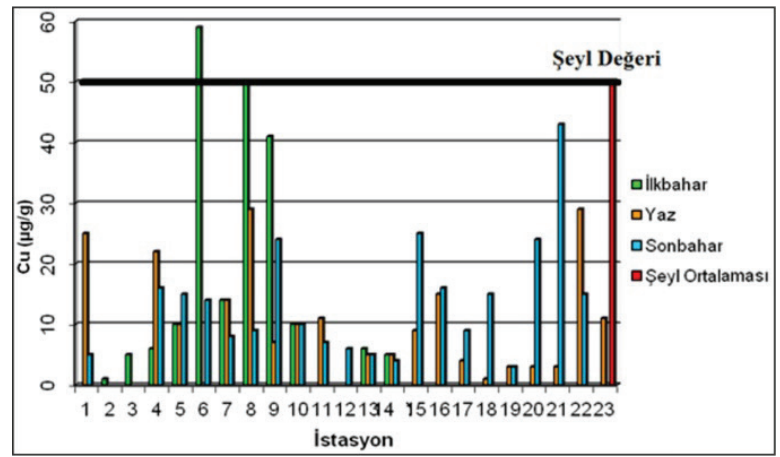

Şekil 6. Güllük Körfezi yüzey sedimentlerinde toplam $\mathrm{Cu}$ içerikleri $(\mu \mathrm{g} / \mathrm{g})$.

Figure 6. Cu contents in surface sediments from Güllük Bay $(\mu g / g)$.

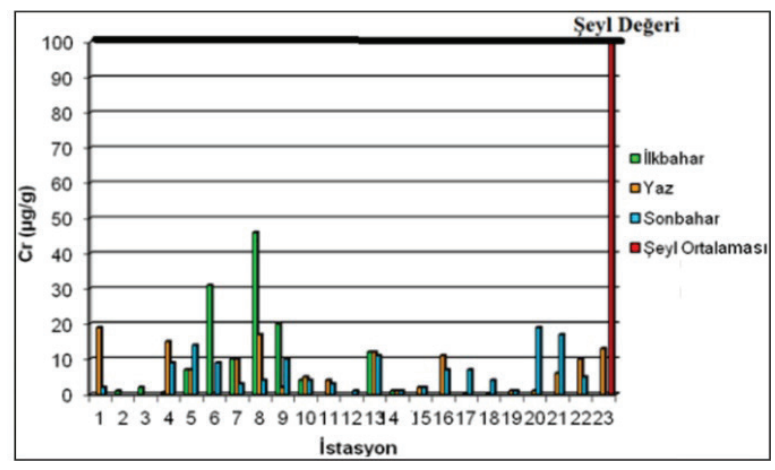

Şekil 7. Güllük Körfezi yüzey sedimentlerinde toplam Cr içerikleri $(\mu \mathrm{g} / \mathrm{g})$.

Figure 7. Cr contents in surface sediments from Güllük Bay $(\mu g / g)$.

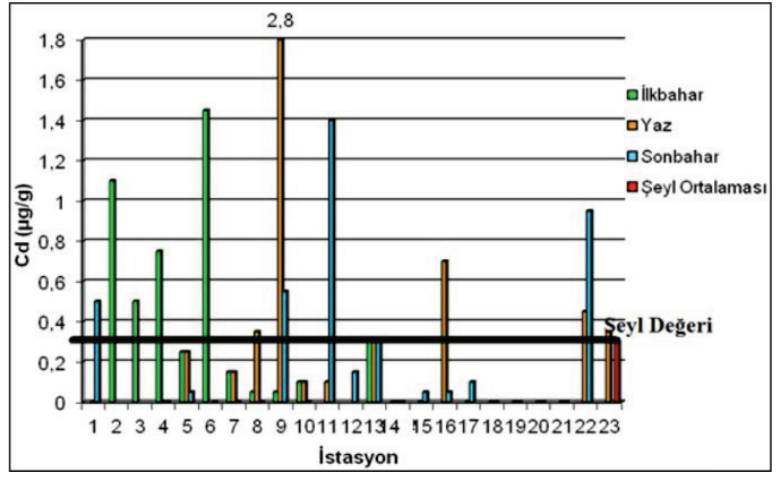

Şekil 8. Güllük Körfezi yüzey sedimentlerinde toplam Cd içerikleri $(\mu \mathrm{g} / \mathrm{g})$.

Figure 8. Cd contents in surface sediments from Güllük Bay $(\mu g / g)$.

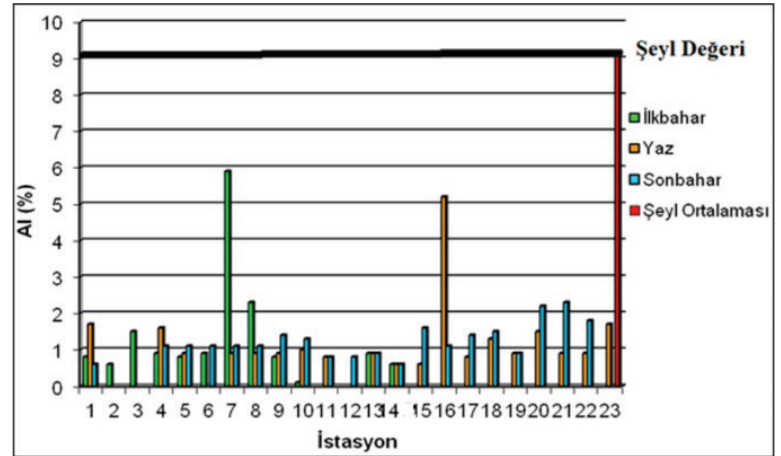

Şekil 9. Güllük Körfezi yüzey sedimentlerinde toplam $\mathrm{Al}$ içerikleri (\%).

Figure 9. Al contents in surface sediments from Güllük Bay (\%).

\section{SONUÇLAR VE TARTIŞMA}

Denizel ortamlarda yüzey sedimentleri kirlenme faktörü (CF) değerine göre sinıflandırılmaktadır (Li vd., 2000; Pekey vd., 2004). Buna göre CF değeri 4 ayrı grupta sinıflandırılır. $\mathrm{CF}<1$ ise kirlenmemiş, $1<\mathrm{CF}<3$ ise orta derecede kirlenmiş, $3<\mathrm{CF}<6$ ise önemli derecede kirlenmiş ve $\mathrm{CF}>6$ ise oldukça yüksek derecede kirlenmiş olarak yorumlanmaktadır (Hakanson, 1980). CF değeri aşağıdaki formüle göre hesaplanır.

$\mathrm{CF}=\mathrm{C}_{\text {metal }} / \mathrm{C}_{\mathrm{o}}$

$\mathrm{C}_{\text {metal }}$ : Sediment örneğindeki metal konsantrasyonu $\mathrm{C}_{\mathrm{o}}$ : Metalin dünya şeyl ortalama değeri

formülüne göre hesaplanır. Formüle göre yapılan hesaplamalarla tüm ölçüm dönemlerinde bütün istasyonlarda yüzey sedimentlerinin $\mathrm{Cu}, \mathrm{Cr}$ ve As elementleri yönünden kirlenmemiş olduğu tespit edilmiştir. Söz konusu elementlerin toplam içeriklerinin şeyl ortalamasının altında olduğunun belirlenmesi de bu sonucu desteklemektedir. Buna karş1l1k, Pb yönünden ilkbahar döneminde Çam Limanı'nın orta derecede, Sarıçay deresi ağzında oldukça yüksek ve yaz döneminde ise yine Sarıçay deresi ağzında orta derecede kirlenmiş olduğu 
belirlenmiştir. Cd yönünden Kazıklı açığı, Kazıklı ve Çam Limanlarının, yaz döneminde Asım Körfezi ve Sarıçay deresi ağzının, sonbaharda ise Panayır Adası Kuzeyi ve Sarı Çay deresi ağzının orta derecede kirlenmiş olduğu görülmüştür. Zn yönünden ise ilkbahar döneminde Teke Burnu ve referans istasyonu dişında orta derece bir kirlenme belirlenirken, yaz döneminde İncegöl Burnu, Güvercinlik ve Büyük Tavşan Adası güneyinde ve sonbaharda Yük Limanı'nda orta derecede kirlenme tespit edilmiştir. Benzer şekilde $\mathrm{Pb}, \mathrm{Cd}$ ve $\mathrm{Zn}$ metalleri yönünden kirlenmelerin görüldüğü aynı dönemlerde toplam $\mathrm{Pb}, \mathrm{Cd}$ ve $\mathrm{Zn}$ içerikleri de şeyl ortalamasının üzerinde bulunmuştur. Dolayısıyla analizler ve hesaplamalar sonucu elde edilen veriler birbirini desteklemektedir. $\mathrm{Bu}$ çalışma, Güllük Körfezi’nde Dalman vd. (2006) tarafindan yapılan çalışma ile karşılaştırıldığında sonuçların genel olarak uyumlu olduğu; farklı olarak Sarıçay deresi ağzındaki örneklerde özellikle Pb, Cdve Zn konsantrasyonlarının yüksek olduğu görülmüştür (Çizelge 1). Ayrıca Gökova Körfezi ve Muğla ili ve çevresinde yapılan kirlilik izleme çalışmalarında metal birikimlerinde termik santrallerin de etkili olduğu dikkati çekmektedir (Baba vd., 2003; Tuna vd., 2005; Balk1s vd., 2010). Sonuç olarak, yüzey sedimentlerindeki yüksek $\mathrm{Pb}$, $\mathrm{Cd}$ ve $\mathrm{Zn}$ değerleri Güllük Körfezi'ne özellikle Sarıçay deresi olan karasal kaynaklı antropojenik girdilere, limanlardaki deniz taşımacılığına ve turizm aktivitelere işaret etmektedir. Buna karşılık, körfez sedimentlerinde şeyl ortalaması altındaki Al içerikleri ise yüzey sedimenti örneklerinin kaba taneli yani karbonatça zengin olmasından kaynaklanmakta olup, körfeze yakın olan mermer yatakları ile ilişkili olduğu düşünülmektedir.

Çizelge 1. Yüzey sedimentlerinde toksik metal kirliliği.

Table 1. Toxic metal pollution in surface sediments

\begin{tabular}{lcccccc}
\hline \multirow{2}{*}{ Çalışma Alanları } & $\mathbf{A l}$ & $\mathbf{C r}$ & $\mathbf{C u}$ & $\mathbf{Z n}$ & $\mathbf{P b}$ & $\mathbf{C d}$ \\
\cline { 2 - 7 } & $\mathbf{9}$ & & & $\boldsymbol{\mu g} / \mathbf{g}$ & \\
\hline Erdek Körfezi (Mülayim vd., 2012) & $1,14-8,61$ & $2,2-172$ & $<0,01-24$ & $18-106$ & $2-172$ & $0,52-0,77$ \\
Bandırma Körfezi (Mülayim vd., 2012) & $1,83-5,64$ & $3,2-229$ & $0,08-27$ & $25-80$ & $17-36$ & $0,57-0,86$ \\
Erdek Körfezi (Balkıs ve Çağatay, 2001) & $1,1-9,2$ & $11-238$ & $3-52$ & $34-272$ & $19-61$ & - \\
Gemlik Körfezi (Algan vd., 2004) & $3,7-8,7$ & $53-152$ & $6-107$ & $33-410$ & $17-85$ & - \\
İzmit Körfezi (Balkıs vd., 2007) & $2,3-11,4$ & $34-77$ & $11-42$ & $84-306$ & $23-52$ & - \\
İstanbul Şehri Kıyıları (Algan vd., 1999) & $0,8-8$ & $11-509$ & $5-80$ & $48-237$ & $12-58$ & - \\
İzmir Körfezi (Küçüksezgin vd., 2006) & - & $29-316$ & $13-49$ & $45-114$ & $14-113$ & $0,01-0,33$ \\
Gökova Körfezi (Balkıs vd., 2010) & $5-34$ & $18-1012$ & $0,01-52$ & $38-55$ & $2-40$ & $<0,01-1,6$ \\
Güllük Körfezi (Dalman vd., 2006) & - & - & $20-30$ & $34-159$ & $19-21$ & $0,45-0,69$ \\
Güllük Körfezi (Bu çalışma) & $0,1-5,9$ & $0,1-46$ & $1-59$ & $10-259$ & $0,1-209$ & $<0,01-1,8$ \\
\hline
\end{tabular}




\section{EXTENDED SUMMARY}

Güllük Bay is surrounded by small settlements such as Torba, Güvercinlik and Güllük. There are no industrial activities in the vicinity. Fishery and tourism are the main livelihood activities around the bay. Güllük Port is a dense transport location for bauxite and feldspar minerals in the bay. In this study, total lead $(P b)$, cadmium $(C d)$, chromium $(\mathrm{Cr})$, copper $(\mathrm{Cu})$, zinc $(\mathrm{Zn})$, arsenic $(\mathrm{As})$ and aluminum (Al) contents were investigated in the surface sediments in order to determine current contamination in Güllük Bay. For this purpose, surface sediments were collected with Ekman Grab (Hydrobios 15x15) seasonally from the bay (May, June, July and September) in 2011 and 2012. Strong acid $\left(\mathrm{HNO}_{3} \mathrm{HF}+\mathrm{HClO}_{4}\right)$ digestion was used for metal analysis after drying in a freezedryer. Total metal concentrations were measured by atomic absorption spectrophotometer. It was observed that total metal contents changed between 1 and $209 \mu \mathrm{g} / \mathrm{g} ; 10$ and $259 \mu \mathrm{g} / \mathrm{g} ; 1$ and $59 \mu \mathrm{g} / \mathrm{g} ; 0.1$ and $46 \mu \mathrm{g} / \mathrm{g} ;<0.01$ and $2.8 \mu \mathrm{g} / \mathrm{g}$, $<0.01$ and $0.4 \mu \mathrm{g} / \mathrm{g}, 0.6 \%$ and $5.9 \%$ for $\mathrm{Pb}$, $\mathrm{Zn}, \mathrm{Cu}, \mathrm{Cr}, \mathrm{Cd}$, As and Al, respectively. Copper, $\mathrm{Cr}$ and As concentrations were lower than the background values, contrary to higher $\mathrm{Cd}, \mathrm{Pb}$ and $\mathrm{Zn}$ contents of the bay surface sediments in all the sampling periods. In other words, Güllük bay is an unpolluted area for $\mathrm{As}, \mathrm{Cr}$ and $\mathrm{Cu}$, while it is moderately polluted with $\mathrm{Cd}, \mathrm{Pb}$ and $\mathrm{Zn}$. These high metal values indicate that there are anthropogenic (domestic and industrial) inputs via Sarlçay creek and both maritime transport (especially at Kazk, Yük and Çam Ports) and tourism wastes in Güllük Bay. In contrast, the low Al content could indicate both natural and anthropogenic terrestrial inputs from a marble mining zone close to the bay.

\section{KATKI BELİRTME}

Makalenin üretildiği bilimsel veriler TÜBİTAK tarafından desteklenen 110Y243 no'lu proje kapsamında elde edilmiştir.

\section{ORCID}

Nuray Çă̆lar (Balkus) (D) https://orcid.org/0000-0001-7608-6339 Abdullah Aksu (D https://orcid.org/0000-0003-1368-5689 Gülşen Altuğ (D) https://orcid.org/0000-0003-3251-7699

\section{DEĞİNILEN BELGELER / REFERENCES}

Aksu, A., Taşkın, Ö.S., 2012. Organochlorine residue and toxic metal $(\mathrm{Pb}, \mathrm{Cd}$ and $\mathrm{Cr})$ levels in the surface sediments of the Marmara Sea and the coast of Istanbul, Turkey. Marine Pollution Bulletin, 64 (5), 1060-1062.

Algan, O., Çağatay, N., Sarıkaya, H.Z, Balkıs, N., Sar1, E., 1999. Pollution monitoring using marine sediments: A case study on the Istanbul metropolitan area. Turkish Journal of Engineering and Environmental Sciences, 23 (1), 39-48.

Algan, O., Balkıs, N., Çağatay, M. N., Sarı, E. 2004. The sources of metal contents in the shelf sediments from the Marmara Sea, Turkey. Environmental Geology, 46, 932-950.

Altuğ, G., Balkıs, N., Çardak, M., Gürün S., Çiftçi Türetken, P.S., Kalkan, S., Hulyar, O., 2013. Güllük Körfezi Ekosisteminin Bakteriyolojik Analizlerle Araştırılması. Türkiye Bilimsel ve Teknolojik Araştırma Kurumu (TÜBİTAK), Proje No: 110Y243, (yayımlanmamış).

Baba, A., Kaya, A., Birsoy, Y.K., 2003. The effect of Yatağan Thermal power plant (Muğla, Turkey) on the quality of surface and groundwaters. Water Air and Soil Pollution, 149 (1-4), 93-111.

Balcığlu, E.B., Aksu, A., Balkıs, N., Öztürk, B., 2014. T-PAH contamination in Mediterranean mussels (Mytilus galloprovincialis, Lamarck, 1819) at various stations of the Turkish Straits System. Marine Pollution Bulletin 88 (1-2), 344-346.

Balkıs, N., Çağatay M.N., 2001. Factors controlling metal distributions in the surface sediments of the Erdek Bay, Sea of Marmara, Turkey. Environment International, 27, 1-13.

Balkıs, N., Algan O., 2005. Marmara Denizi Yüzey Sedimentlerinde (Şelf Alanı) Metallerin Birikimi ve Denetleyen Mekanizmalar, (Deniz Kirliliği Analiz Yöntemleri İlgili Uluslararası Sözleşmeler, Editörler: Güven, K.C., Öztürk, B.). TÜDAV Yayınları No:21, 177-204. 
Balk1s, N., Senol, E., Aksu, A., 2007. Trace metal distributions in water column and surface sediments of Izmit Bay (Turkey) after Marmara (Izmit) earthquake. Fresenius Environmental Bulletin, 16 (8), 910-916.

Balkıs, N., Aksu A., Okuş E., Apak, R., 2010. Heavy metal concentrations in water, suspended matter, and sediment from Gökova Bay, Turkey. Environmental monitoring and assessment, 167 (1-4), 359-370

Brayn, G.W., 1971. The effects of heavy metals on marine and easturaine organisms. Proceedings of the Royal Society of London, 389-410.

Brayn, G.W., 1976. Heavy metal contamination in the sea, (Marine Pollution, Editör: Johnson R.). Academic Press, London 185-302.

Dalman, Ö., Demirak, A., Balc1, A., 2006. Determination of heavy metals $(\mathrm{Cd}, \mathrm{Pb})$ and trace elements $(\mathrm{Cu}, \mathrm{Zn})$ in sediments and fish of the Southeastern Aegean Sea (Turkey) by atomic absorption spectrometry. Food Chemistry, 95 (1), 157-162.

Gailer, J. 2007. Arsenic-selenium and mercuryselenium bonds in biology. Coordination Chemistry Reviews 251 (1-2), 234-254.

Güler Ç., Çobanoğlu Z., 1994. Çocuk ve Çevre. Çevre Sağlığı Temel Kaynak Dizisi No:23, T.C. Sağlık Bakanlığı Temel Sağlık Hizmetleri Genel Müdürlüğü, Ankara, 24.

Hakanson, L., 1980. An ecological risk index for aquatic pollution control a sedimentological approach. Water Research, 14 (8), 975-1001.

Krauskopf, K.B. 1979. Introduction to Geochemistry. McGraw-Hill, New York, 617 s.
Küçüksezgin, F., Kontas, A., Altay, O., Uluturhan, E., Darilmaz, E., 2006. Assessment of marine pollution in Izmir Bay: Nutrient, heavy metal and total hydrocarbon concentrations. Environment International, 32(1), 41-51.

Li, X., Shen, Z., Wai, O.W.H., Li, Y., 2000. Chemical partitioning of heavy metal contaminants in sediments of the Pearl River Estuary. Chemical Speciation and Bioavailability, 12, 17-25.

Loring, D.H. ve Rantala, R.T.T., 1992. Manual for the geochemical analyses of marine sediments and suspended particulate matter. Earth-Science Reviews, 32, 235-283.

Mülayim, A., Balkıs, N., Balkıs, H., Aksu, A., 2012. Distributions of total metals in the surface sediments of the Bandirma and Erdek Gulfs, Marmara Sea, Turkey. Toxicological \& Environmental Chemistry, 94 (1), 56-69.

Pekey, H., Karakaş, D., Ayberk, S., Tolun, L., Bakoğlu, M., 2004. Ecological risk assessment using trace elements from surface sediments of Izmit Bay (Northeastern Marmara Sea) Turkey. Marine Pollution Bulletin, 48, 946-953.

Taşkın, Ö.S., Aksu, A. ve Balkıs, N., 2011. Metal $(\mathrm{Al}, \mathrm{Fe}, \mathrm{Mn}$ and $\mathrm{Cu}$ ) distributions and origins of polycyclic aromatic hydrocarbons (PAHs) in the surface sediments of the Marmara Sea and the coast of Istanbul, Turkey. Marine Pollution Bulletin, 62 (11), 2568-2570.

Tuna, L.A., Yağmur, B., Hakerlerler, H., Kılınç, R., Yokas, İ., Bürün, B., 2005. Muğla Bölgesi’ndeki Termik Santrallerinden Kaynaklanan Kirlilik Üzerine Araştırmalar. Muğla Üniversitesi, Bilimsel Araştırma Projesi-Kesin Raporu, Muğla, $79 \mathrm{~s}$.

TÜIKK, 2018. http://www.tuik.gov.tr/PreTablo.do?alt_ $\mathrm{id}=1047$ 